\title{
Occurrence of the oribatid mite Trhypochthoniellus longisetus longisetus (Acari: Trhypochthoniidae) on tilapia Oreochromis niloticus
}

\author{
A. Sonia Olmeda ${ }^{1}$, M. Mar Blanco ${ }^{2}$, José L. Pérez-Sánchez ${ }^{1}$, Mónica Luzón ${ }^{1}$, \\ Morris Villarroel $^{3}$, Alicia Gibello ${ }^{2, *}$
}

\begin{abstract}
${ }^{1}$ Grupo de Investigación Epicontrol, and ${ }^{2}$ Laboratorio de Ictiopatología, Departamento de Sanidad Animal, Facultad de Veterinaria de la Universidad Complutense de Madrid, Avda. Puerta de Hierro s/n, 28040 Madrid, Spain ${ }^{3}$ Departamento de Producción Animal, E.T.S.I. Agrónomos de la Universidad Politécnica de Madrid, Avda. Puerta de Hierro s/n, 28040 Madrid, Spain
\end{abstract}

\begin{abstract}
Mites as parasites infesting fish have been described in a few case reports involving Histiostoma anguillarum, $H$. papillata, and Schwiebea estradai. We describe the unexpected occurrence of oribatid mites of the genus Trhypochthoniellus on farmed tilapia Oreochromis niloticus. The fish had mites on the skin, fins, and gills, as well as in the mouth. The morphological characteristics of the mites, observed by optical and scanning electron microscopy, were consistent with those described for T. longisetus longisetus. All stages of development were observed, suggesting that the mites were able to actively reproduce on fish.
\end{abstract}

KEY WORDS: Fish parasite $\cdot$ Mite $\cdot$ Oribatida $\cdot$ Trhypochthoniellus longisetus $\cdot$ Tilapia $\cdot$ Oreochromis niloticus $\cdot$ Aquatic animal health

\section{INTRODUCTION}

Many fishes in wild populations have parasites, but most do not represent a serious health threat. However, farmed fishes are subjected to environmental stress, which makes them more sensitive than wild fishes to parasitic diseases. Fish parasites belong to many different taxonomic groups, including Protozoa, Monogenea, Trematoda (Digenea), Cestoidea, Nematoda, Annelida, Crustacea, Mollusca, and Acarina. Very little is known about mite (Acarina) infestation of fishes, and there are few records listed in journals. These studies indicate, however, that massive infestation, although infrequent, has negative effects on fish health (Fain \& Belpaire 1985, Fain \& Ferrando 1990, Halliday \& Collins 2002).

The habitat and behavior of fishes do not contribute to mite infestation, and some authors consider mites to be unusual parasites of fish, whereas for others, mites are not fish parasites at all (Halliday \& Collins 2002). However, under certain environmental conditions, mites may proliferate and colonize weak or stressed fishes, attaching to the mucous membranes and causing serious damage. Several genera of mites have been isolated from the skin, gills, and esophagus of fishes in Europe, Australia, and North America (Heckmann 2003), in some cases associated with high fish mortality. In one report, Histiostoma papillata (Histiostomatidae, Astigmata) attacked and apparently killed juvenile Murray cod Maccullochella peelii peelii held in a recirculation aquaculture system (Halliday \& Collins 2002). Likewise, $H$. anguillarum was described as a mite that parasitizes the gills of young farmed freshwater eels Anguilla anguilla (Fain \& Belpaire 1985). Mortality was also high in trout Salmo trutta fario from a fish farm and a river; these fish had Schwiebea (Jacoti- 
etta) estradai mites on the skin, gills, and in the intestine (Fain \& Ferrando 1990). In the present work, we describe, for the first time, the occurrence of the oribatid mite Trhypochthoniellus longisetus longisetus on farmed tilapia Oreochromis niloticus. This oribatid mite is an aquatic species that lives in a wide range of freshwater habitats (from bogs to aquariums) commonly associated with vegetable organic material or aquatic plants (Lange \& Tolstikov 1999, Kuriki 2005). Specimens of Trhypochthoniellus sp. have also been previously found in the gills of juvenile Atlantic salmon Salmo salar from a river system (Hare \& Burt 1975).

\section{MATERIALS AND METHODS}

Farmed tilapia were held at the Animal Production Field Station of the Polytechnic University of Madrid, Spain. Tilapia were held in a recirculation aquaculture system consisting of 16 fiberglass tanks interconnected with a solids separator and biofilter. Each tank (120 l capacity) was properly aerated and kept at a temperature $( \pm \mathrm{SD})$ of $21.8 \pm 0.7^{\circ} \mathrm{C}$ and photoperiod of $12 \mathrm{~h}$ light:12 h dark. At the time of disease and our investi-

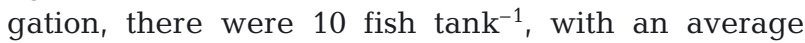
$( \pm \mathrm{SD})$ weight of $56.5 \pm 13.4 \mathrm{~g}$, and fish were fed twice a day with pelleted commercial feed (32\% protein, Dibaq). The physical and biological properties of the water were not considered to be outside the normal ranges for tilapia (oxygen $>6 \mathrm{ppm}, \mathrm{pH} 7$ to 8 , ammonia and nitrites $<0.01 \mathrm{ppm}$, and nitrates $<150 \mathrm{ppm}$ ).

Mites collected from the skin of the diseased fish were examined using a Nikon eclipse E-400 optical microscope for morphological data. For this purpose, 16 mites were mounted in polyvinyl alcohol (PVA) on microscope slides. For examination of mite taxonomic characteristics, samples were prepared and mounted for scanning electron microscopy (SEM) on a JEOL JSM 6400 (see Fig. 2C,D). The mites were pre-fixed in $3 \%$ glutaraldehyde in phosphate buffer $(\mathrm{pH} 7.4)$ for $3 \mathrm{~h}$, washed twice in phosphate buffer ( $\mathrm{pH} 7.4$ ), and dehydrated in an alcohol series $(50,70,80,90$, and $100 \%$ ) for $15 \mathrm{~min}$. Further routine treatments were processed for SEM at the 'Luis Bru' Electronic Microscope Laboratory at Complutense University, Madrid.

\section{RESULTS AND DISCUSSION}

Significant signs of external parasitism, anomalous swimming, and irritation were detected in 4 of the tanks. In 1 tank, 2 fish had died, while most of the remaining fish were alive but lethargic. These fish were taken to Complutense University for diagnosis.

Examination of the affected fish revealed the presence of numerous mites attached to the body surface, fins, gills, and inside the mouth, with up to 15 mites $\mathrm{cm}^{-2}$ in some areas (Fig. 1). Of the 16 mites analyzed, a total of 10 adults were identified as females (average size $523 \times 294 \mu \mathrm{m})$. Of the 6 immature mites, 2 were identified as larvae, which are hexapods (average size, $222 \times 104 \mu \mathrm{m}$ ), and 4 were identified as nymphs (average size, $443 \times 140 \mu \mathrm{m})$. The high numbers of mites on fish mucus and the presence of all developmental stages, including gravid females (Fig. 2A,B) and free eggs, suggest that mites were reproducing on the fish. The number of eggs ranged from 1 to 4 female $^{-1}$. Morphological data for dorsal and ventral sides were obtained by SEM (Fig. 2C,D). The mites were identified as the oribatid mite Trhypochthoniellus longisetus

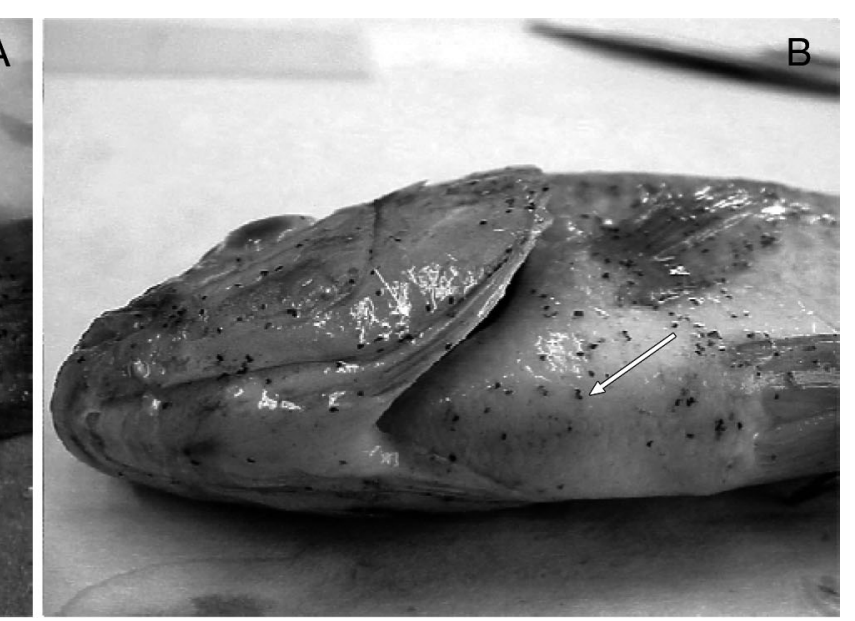

Fig. 1. Trhypochthoniellus longisetus longisetus on Oreochromis niloticus. Gross appearance of mites (arrows) on the skin of tilapia. (A) Lateral and (B) ventral view. AnF = anal fin, $\mathrm{CP}=$ caudal peduncle 

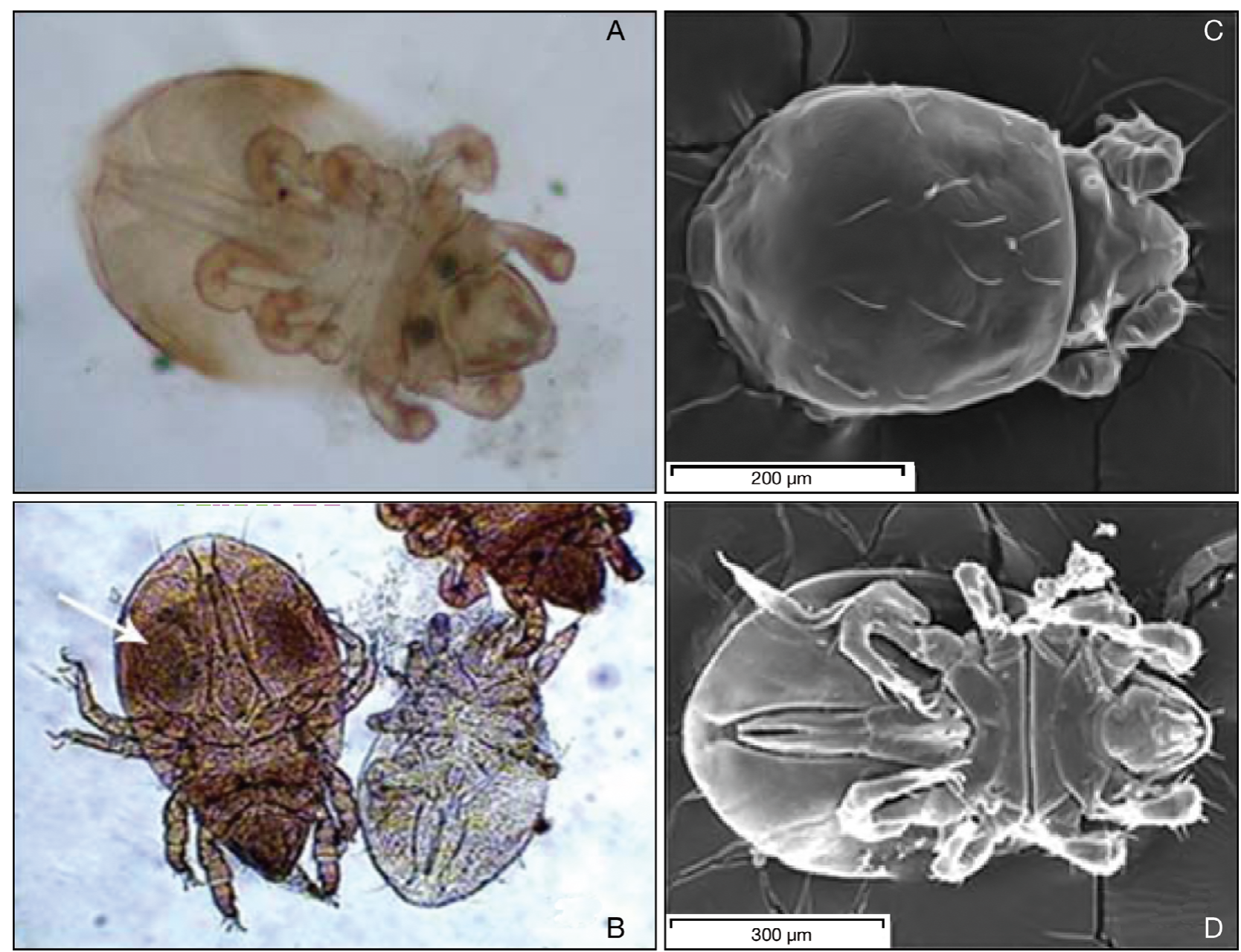

Fig. 2. Trhypochthoniellus longisetus longisetus from Oreochromis niloticus. Light micrographs of cleared, slide-mounted specimens of mites from fish skin: (A) adult female mite in ventral position and (B) adult female mite with developing eggs (arrow) and 1 nymph. Scanning electron micrographs of mites in (C) dorsal and (D) ventral positions. Scale bars show the original magnification

longisetus based on taxonomic characteristics originally described for this species (Berlese 1904, Aoki 1964, Colloff \& Halliday 1998), and on the setae formula of the epimeral region 3-1-3-2 (Fig. 2C,D) subsequently described for this mite (Weigmann 1999, Kuriki 2005).

According to the mite classification by Subías (2010), the genus Trhypochthoniellus (Willmann, 1928) comprises 7 species, including T. longisetus, which in turn includes 3 subspecies: one with a wide distribution, T. longisetus longisetus (Holarctic, Australian, Ethiopian, and Neotropical), and 2 that are more geographically restricted ( $T$. longisetus brasiliensis and T. longisetus canadensis). T. longisetus is a parthenogenetic species, so there are no males, as we observed in our samples of mites. The subspecies $T$. longisetus longisetus (junior synonym of $T$. crassus
[Warburton \& Pearce 1905]; Hydronothrus crispus [Aoki 1964]; Hydronothrus aquariorum [Fain \& Lambrechts 1987]; Trhypochthonius setosus [Willmann 1928]; in addition to other synonymous names, Subías 2010) is commonly found in vegetation at the edge of lakes and ponds, where it seems to feed primarily on cellulose of living green plants or decaying vegetation, such as dead leaves of Hibiscus tiliaceus (Aoki 1964). This oribatid mite is widespread, extremely common in aquatic habitats that are rich in organic material, such as some natural freshwater, mires, high-mounted drinking-water tanks, and swimming pools (Tagami et al. 1992, Kuriki 2005, Perotti et al. 2009). In fact, because it is a common contaminant in indoor pools in some countries, such as Japan, it has recently been considered to be an allergen of public health significance (Robinson 2005). 
Owing to their small size and great plasticity, mites can adapt to a wide range of vertebrate hosts (from fishes to mammals) and habitats (Fain 1994). Mites have evolved and adapted to almost every habitat on land and they are found in every kind of freshwater. Their adaptation to aquatic conditions evolved independently in different taxa: Mesostigmata, Astigmata, Oribatida, and Prostigmata (Proctor 2004, Weigmann \& Deichsel 2006, Schatz \& Behan-Pelletier 2008). Ecologically, mites belonging to the Oribatida subgroup are primarily terrestrial, predominantly free-living detritivores and fungivores, and only about $1 \%$ of all known species (some species of a few oribatid genera, including Trhypochthoniellus) are truly aquatic (Schatz \& Behan-Pelletier 2008). Aquatic oribatids are present in standing and running water, but all are non-swimming, and have diets similar to their terrestrial relatives (Proctor 2009).

Oribatid mites have previously been associated with parasitism of fishes (Hare \& Burt 1975, Choudhury et al. 2004), but, to our knowledge, the present work is the first case that describes infestation of farmed tilapia by oribatid mites (Trhypochthoniellus longisetus longisetus). It is not clear how these mites reached the freshwater, but once they had, the recirculating system provided an ideal environment for mite growth: warmth, nutrient-rich water, and abundant surfacehosts. The fact that all stages of development, including free eggs, were observed could indicate that the mites were able to actively reproduce on fish, and suggests an adaptation of mite to host. Probably, these mites were feeding on bacterial slime, fungal remains or spores, and yeast growth on the surface of the fish or attached to the fish mucus. Although it seems very unlikely that mites would feed directly on a corpse, there is at least 1 report of $T$. longisetus longisetus associated with the necrotic skin of discus fish Symphysodon sp. (Fain \& Lambrechts 1987); however, the ingestion of animal debris by oribatid mites is rare and could be considered accidental. In the present study, $T$. longisetus longisetus seems to be an opportunistic feeder that reached high densities on the fish, having negative effects on the health of these animals. Heavily infested fish may become seriously injured because of the alterations in the fins and mucus and may even suffer mechanical asphyxia as a result of the infestation of the gills.

\section{CONCLUSIONS}

Trhypochthoniellus longisetus longisetus has been found, for the first time, on farmed tilapia. All stages of development were observed in the mites analyzed, suggesting that they were able to actively reproduce on fish. Although the presence of this mite on tilapia is not part of its normal biological life cycle, the unexpected high proliferation of this mite could have negative effects on fish health.

Acknowledgements. The authors thank F. Valcárcel (CISAINIA de Valdeolmos, Madrid) and R. A. Norton (SUNY College of Environmental Sciences \& Forestry, Syracuse, New York) for their generous help in confirming the morphological identification of the mites and for their comments. This work was supported by the Ministerio de Ciencia e Innovación, Project AGL2009-12447.

\section{LITERATURE CITED}

Aoki JI (1964) A new aquatic oribatid mite from Kauai Island. Pac Insects 6:483-488 http://hbs.bishopmuseum.org/pi/ pi6-3.htm

Berlese A (1904) Acari nuovi. Manipulus III. Redia 2:10-32

> Choudhury A, Hoffnagle TL, Cole RA (2004) Parasites of native and nonnative fishes of the Little Colorado River, Grand Canyon, Arizona. J Parasitol 90:1042-1053

Colloff MJ, Halliday RB (1998) Oribatid mites: a catalogue of the Australian genera and species. CSIRO Publications, Melbourne

Fain A (1994) Adaptation, specificity and host-parasite coevolution in mites (Acari). Int J Parasitol 24:1273-1283

Fain A, Belpaire C (1985) A new mite (Acari, Anoetidae) parasitizing the gills of young eels Anguilla anguilla (L.). Bull Ann Soc R Belg Entomol 121:285-292

Fain A, Ferrando M (1990) A new species of Schwiebea Oudemans (Acari, Acaridae) parasitizing the trout Salmo trutta fario in Spain. Rev Iber Parasitol 50:67-71

Fain A, Lambrechts L (1987) Observations on the acarofauna of fish aquariums. I. Mites associated with discus fish. Bull Ann Soc R Belg Entomol 123:87-102

Halliday RB, Collins RO (2002) Histiostoma papillata sp. n. (Acari: Histiostomatidae), a mite attacking fish in Australia. Aust J Entomol 41:155-158

Hare GM, Burt MDB (1975) Identification, host sites and biology of parasites infecting juvenile Atlantic salmon (Salmo salar) in the Miramichi River System, New Brunswick. Fish Mar Serv Tech Rep 581

Heckmann R (2003) Other ectoparasites infesting fish; copepods, branchiurans, isopods, mites and bivalves. Aquac Mag 29(6):20-31

Kuriki G (2005) Oribatid mites from several mires in Northern Japan. I. Two new species of the genus Trhypochthoniellus (Acari: Oribatida). J Acarol Soc Jpn 14:83-92

Lange AB, Tolstikov AV (1999) Ovoviviparity, prelarva and the peculiarities of eclosion in fresh-water oribatid mites Trhypochthoniellus setosus (Will.) and Hydrozetes lemnae (Coggi). Acarina 7:13-21. Also available at http://insects. ummz.lsa.umich.edu/acarina/

> Perotti MA, Goff ML, Baker AS, Turner BD, Braig HR (2009) Forensic acarology: an introduction. Exp Appl Acarol 49: $3-13$

> Proctor H (2004) Aquatic mites: from genes to communities an introduction. Exp Appl Acarol 34:1-2

Proctor HC (2009) Can freshwater mites act as forensic tools? Exp Appl Acarol 49:161-165

Robinson WH (2005) Handbook of urban insects and arachnids. Cambridge University Press, Cambridge

Schatz H, Behan-Pelletier V (2008) Global diversity of ori- 
batids (Oribatida: Acari: Arachnida). Hydrobiologia 595: $323-328$

Subías LS (2010) Listado sistemático, sinonímico y biogeográfico de los ácaros oribátidos (Acariformes, Oribatida) del mundo. Universidad Complutense, Madrid. Available at www.ucm.es/info/zoo/Artropodos/Catalogo.pdf

Tagami K, Ishihara T, Hosokawa J, Ito M, Fukuyama K (1992) Occurrence of aquatic oribatid and astigmatid mites in swimming pools. Water Res 26:1549-1554

Warburton C, Pearce NDF (1905) On new and rare British mites of the family Oribatidae. Proc Zool Soc Lond 1:564-569

Editorial responsibility: Sven Klimpel,

Frankfurt/Main, Germany
Weigmann G (1999) Morphological variability in populations of a thelytokous mite, Trhypochthoniellus longisetus (Oribatida), with notes on synonymy. In: Bruin J, van der Geest LPS, Sabelis M (eds) Ecology and evolution of the Acari. Kluwer Academic, Dordrecht, p 581-586

Weigmann G, Deichsel R (2006) Acari: limnic Oribatida. In: Gerecke R (ed) Chelicerata: Araneae, Acari I. Süßwasserfauna von Mitteleuropa, Vol 7. Spektrum, Munich, p 89112

Willmann C (1928) Neue Oribatiden I. Org Dtsch Zool Ges 76: $1-5$

Submitted: August 30, 2010; Accepted: November 9, 2010

Proofs received from author(s): February 17, 2011 